\title{
The Impact of Urbanization on the Annual Average Temperature of the Past 60 Years in Beijing
}

\author{
Yong Wang, ${ }^{1}$ Wei Ji, ${ }^{1,2}$ Xinfang Yu, ${ }^{1}$ Xinliang Xu, ${ }^{1}$ Dong Jiang, \\ Zhangang Wang, ${ }^{1}$ and Dafang Zhuang ${ }^{1}$ \\ ${ }^{1}$ State Key Laboratory of Resources and Environmental Information System, Institute of Geographic Sciences and \\ Natural Resources Research, Chinese Academy of Sciences, Beijing 100101, China \\ ${ }^{2}$ University of Chinese Academy of Sciences, Beijing 100049, China \\ Correspondence should be addressed to Wei Ji; jiw@lreis.ac.cn
}

Received 14 February 2014; Accepted 4 April 2014; Published 21 May 2014

Academic Editor: Dawei Han

Copyright (C) 2014 Yong Wang et al. This is an open access article distributed under the Creative Commons Attribution License, which permits unrestricted use, distribution, and reproduction in any medium, provided the original work is properly cited.

\begin{abstract}
Global warming, which is representatively caused by $\mathrm{CO}_{2}$-based greenhouse gases, has caused widespread concern in the global scientific community and gets the high attention of each government in the world. Human activities impact climate change through greenhouse gas emissions and land use changes. The current study on the impact of urbanization on the annual average temperature of the recent 60 years in Beijing was conducted using 1951-2012 temperature data. Anomaly analysis, quadratic polynomial trend method, and moving average method were employed to indicate the temporal variation of temperature. The results showed that average temperature increased both in urban and rural areas. The temperature of urban Beijing increased during the period from 1951 to 2012, especially from 1971 to 1994. The temperature of rural Beijing showed a faster increase than that of the urban area from 1989 to 1998. However, the rate of temperature increase slowed down in recent years. This type of change was temporally consistent with the process of land use change and urbanization in Beijing. Economic restructuring and improvement of urban planning may have been one of the reasons that the regional warming has been slowed down in the rural area.
\end{abstract}

\section{Introduction}

Global warming, which is representatively caused by $\mathrm{CO}_{2}-$ based greenhouse gases, has caused widespread concern in the global scientific community and gets high attention of each government in the world $[1,2]$. IPCC (Intergovernmental Panel on Climate Change) (2013) [2] reported that the increase of carbon dioxide and other greenhouse gases is the major part of the human contribution to global warming. Compared with the fourth assessment report, IPCC's fifth assessment report noted that climate change is more serious than previously thought, and is very likely caused by human behavior. According to the 2013 IPCC report [2], climate change is a definite trend and had not been predicted prior to the 1950s. Since the earliest detailed weather records in the 1850 s, each of the past three decades has broken the high temperature record. The most recent 30 years may be the hottest 30 years since 1400 in the northern hemisphere. From 1880 to 2012 , the average land-ocean surface temperature trended linearly upward, increasing by $0.85^{\circ} \mathrm{C}$. The average temperature from 2003 to 2012 is $0.78^{\circ} \mathrm{C}$ higher than that of 1850 to 1900 (IPCC, 2013). If surface temperatures continue to rise at the present rate, projections for 2050 indicate that the global temperature will rise 2 to $4^{\circ} \mathrm{C}$ north and south polar ice will melt significantly, causing the sea level to rise, and some island nations and coastal cities will be submerged, including the famous international cities of New York, Shanghai, Tokyo, and Sydney.

In recent years, many scholars have studied the influence of human activities (such as urbanization) on climate [3-9]. By comparing observational data from cities and surrounding rural areas, analysis showed that urbanization had a significant impact on the temperature. After analyzing the American Historical Climate Network data (1219 Station), Karl et al. [10] noted that the urbanization influence on temperature is approximately $0.06^{\circ} \mathrm{C}$ (1901-1984) and Kukla et al. [11] noted that in North America the urbanization influence is approximately $0.12^{\circ} \mathrm{C} / 10 \mathrm{a}$. Meanwhile, many domestic scholars were 
studying the effect of Beijing's urbanization on temperature. $\mathrm{Xu}$ [12] noted that the temperature difference between the city and suburb tended to increase. After researching Beijing and surrounding cities' heat island features, Zhang et al. [13] noted that Beijing's urban and suburban temperature changes were in phase, with temperature in suburb always lower than temperature in the city. Beijing city and the suburbs' heat island effect had a noticeable rising trend, comparing the 1990 s with the 1980s. Upon comparing the urban and suburban climates of Beijing, Song et al. [14] found that the average rate of temperature increase in urban area is $0.43^{\circ} \mathrm{C} / 10 \mathrm{a}$ and in suburban is $0.21^{\circ} \mathrm{C} / 10 \mathrm{a}$. Lin and $\mathrm{Yu}[15]$ studied the significant temperature changes in Beijing and noted that its annual variation had large-scale characteristics; there was a change breakpoint in 1981 and the warming rate of the past decade was $0.125^{\circ} \mathrm{C} / 10 \mathrm{a}$. Zhang et al. [16] analyzed 44 years (19612004) of average temperature data from 20 weather stations, and their results showed that Beijing's temperature rose over the 44 years, with a transition in the 1980s after which the warming trend was more significant. Additionally, the warming trend in urban areas was significantly higher than that in the suburbs. Spatially, there was an obvious warming center in urban areas, with warming in January, April, July, and October. The warming trend in urban areas was higher than in the suburbs. Moreover, Yan et al. [17], Zhang et al. [18], and Wang et al. [19] completed in-depth research on the average temperature in Beijing.

In addition to greenhouse gas emissions [20], land use change also has important impact on climate. With the use of numerical simulations and numerical experiments for long term temperature data, many researchers believe that largescale land use or cover change will affect regional and even global climate [21-30].

Through statistical and modeling analysis of the temperature data, summary of the influence of urbanization on climate change, and research on greenhouse gas emissions, land use change, and other human impacts on temperature, previous studies have obtained many different results, but there are still two shortcomings: (1) regarding average temperature trends, all the results showed that since the 1850s, when the observational data began, the general trend is consistent with the global warming trend, and the warming trend has accelerated over the last 50 years $[12,13,15,17-$ $19,25,30]$. However, was the average temperature trend in Beijing area really consistent over the past 60 years? Are there different trends in different stages? So far, there is no clear research result. (2) Related studies have not revealed the impact of human activities (such as the change of land use types caused by urban expansion activities, industrial plant construction, and new road construction) on climate change and their interactions in the process of urbanization.

Using 1951-2012 Beijing temperature data, anomaly analysis, quadratic polynomial trend method, and moving average method, we analyzed the temperatures in Beijing on different temporal scales, explored the temperature trends, determined whether there was temporal consistency between land use change and urbanization, developed an important scientific reference for predicting future Chinese regional temperature variations, and provided a new observational

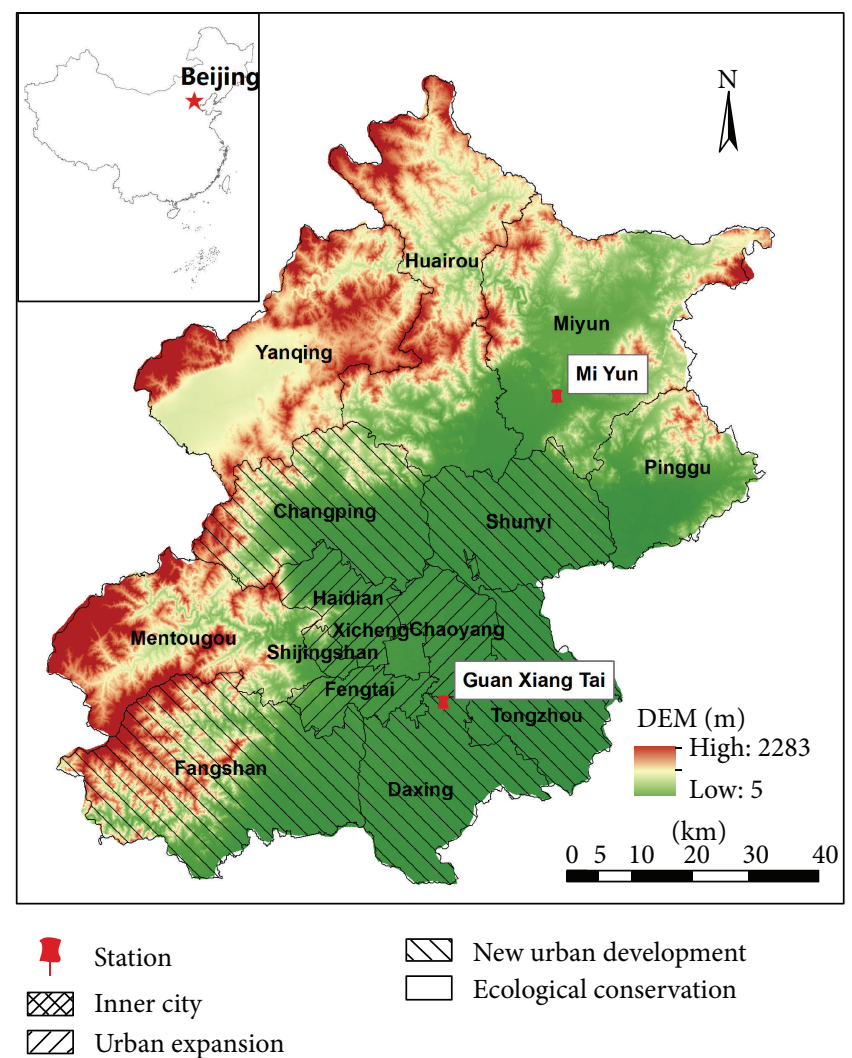

FIgURE 1: The districts, counties, and meteorological stations of Beijing.

basis for studying whether the urban heat island effect and land use status have a significant impact on regional climate change trends.

\section{Data and Material}

2.1. Study Area. Beijing is situated on the northeast edge of the North China Plain, with its city center located at $39^{\circ} 54^{\prime} 20^{\prime \prime} \mathrm{N}$ and $116^{\circ} 25^{\prime} 29^{\prime \prime} \mathrm{E}$. The city covers a land area of 16,411 square kilometers, including 14 districts and 2 counties (Figure 1). The western, northern, and northeastern parts of the area, accounting for approximately $61.4 \%$ of the city, are mountainous and hilly; the remainder is a plain. The city has a typical monsoon-influenced climate, characterized by hot, humid summers due to the East Asian monsoon, and generally cold, windy, dry winters in relation to the vast Siberian anticyclone. Beijing is one place that has experienced high-intensity human activity over the past one hundred years.

According to the urban planning of Beijing, both Dongcheng and Xicheng are traditional core function areas. Chaoyang, Haidian, Fengtai, and Shijingshan are urban expansion districts. Tongzhou, Shunyi, Fangshan, Daxing, and Changping are new urban development districts. Huairou, Pinggu, Mentougou, Miyun, and Yanqing are districts dedicated to ecological conservation. 
2.2. Meteorological Data. Meteorological data came from the China Meteorological Data Sharing Service System (http://cdc.cma.gov.cn/home.do). In this system, there are two meteorological stations in Beijing-Guan Xiang Tai (GXT) and Mi Yun (MY) (Figure 1). GXT, with an altitude of 31.3 meters, is located in southwestern Beijing. It is the only station that participated in the global meteorological data exchange in Beijing. The observational data from GXT were used to represent the climate conditions of the urban and plain areas of Beijing. MY, with an altitude of 71.8 meters, is located in the northern area of the city. It was named for national reference meteorological stations since 1989 and is intended to represent the weather conditions of the rural area. In this study, the monthly mean temperature data from GTX for the period 1951-2012 and from MY for the period 1989-2010 were collected and used to calculate the annual mean and seasonal mean temperatures. According to meteorological convention in Northern China, spring is from March to May, summer is from June to August, autumn is from September to November, and winter is from December to February of the following year. In addition, Mean Temperature Anomaly (MTA), Quadratic Polynomial Fitting (QPF), and a 3-year moving average were also applied to analyze the temporal variation of the mean temperature. The difference between the mean temperatures at GXT and MY was also calculated to analyze the difference between the urban and rural areas from 1989 to 2010.

2.3. Land Use and Land Cover Data. Land use data for Beijing from 1990, 1995, 2000, 2005, and 2010 were provided by the Data Center for Resources and Environmental Sciences (RESDC) of the Chinese Academy of Sciences and were interpreted from Landsat/TM images. Land use was classified into 6 types (cropland, woodland, grassland, water body, built-up land, and unused land) and 25 subtypes. This dataset has been widely applied in studies of land use, with an overall accuracy of $95 \%$ for land use types and $85 \%$ for subtypes and a Kappa coefficient above 0.81 validated by intensive field surveys [31-33].

In addition, a land use change detection matrix and dynamic index were introduced to indicate variations in land use in the city [34]. The land use change detection matrix could intelligibly demonstrate the mutual transformation among the various types of land use. The Land Use Dynamic Index (LUDI) and Bilateral Land Use Dynamic Index (BLUDI) are good indicators of the intensity of land use change as follows:

$$
\begin{gathered}
\operatorname{LUDI}_{i}=\frac{\left(U_{i a}-U_{i b}\right)}{U_{i a}} * \frac{1}{T} * 100 \%, \\
\mathrm{BLUDI}_{i}=\frac{\left(\sum U_{i j}+\sum U_{j i}\right)}{U_{i}} * \frac{1}{T} * 100 \%,
\end{gathered}
$$

where $U_{i a}$ is the area of land use of type $i$ at the beginning of the study period, $U_{i b}$ is the area of type $i$ at the end of the period, $\sum U_{i j}$ is the total area of type $i$ converted into other types, $\sum U_{j i}$ is the total area of type $i$ converted from other

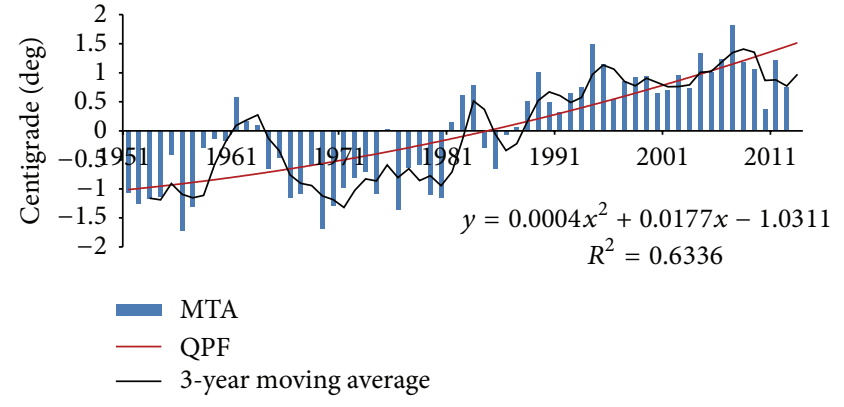

Figure 2: The Mean Temperature Anomaly (MTA), Quadratic Polynomial Fitting (QPF), and a 3-year moving average of the annual mean temperature of Guan Xiang Tai (GXT) in the period of 19512012.

types, $T$ is the study period, and LUDI ${ }_{i}$ and BLUDI ${ }_{i}$ are the dynamic index and bilateral dynamic index of land use type $i$, respectively $[32,35,36]$.

2.4. Socioeconomic Data. The socioeconomic data for this study, including population, building area, length of highway and urban road, and total energy consumption, mainly came from the Beijing Statistical Yearbooks (1978-2012). Data from the fifth and sixth population censuses were also employed in this paper to calculate the Population Growth Rate (PGR) in each town from 2000 to 2010 as follows:

$$
\text { PGR }=\frac{\left(P_{2010}-P_{2000}\right)}{P_{2000}} * 100 \%,
$$

where $P_{2000}$ and $P_{2010}$ represent the population in 2000 and 2010, respectively.

\section{Results and Discussion}

\subsection{The Temporal Variation of Temperature}

3.1.1. Temperature of the Urban Area. Figure 2 shows the temporal variation of the annual Mean Temperature Anomaly (MTA) of GXT from 1951 to 2012. During this period, the average temperature was $12.2^{\circ} \mathrm{C}$ and an increasing temperature trend was apparent according to the Quadratic Polynomial Tendency (QPF) and a 3-year moving average. The MTA was mainly negative before 1980 but became positive after that year. The annual mean temperature increased dramatically from 1971 to 1994 , with the MTA changing from $-1.5^{\circ} \mathrm{C}$ to $1^{\circ} \mathrm{C}$. However, the rate of the MTA increase slowed from 1994 to 2007 and even decreased after 2007 according to the a 3-year moving average.

The seasonal mean temperatures of GXT from 1951 to 2012 were $13.3^{\circ} \mathrm{C}, 25.2^{\circ} \mathrm{C}, 12.5^{\circ} \mathrm{C}$, and $-2.3^{\circ} \mathrm{C}$ for spring, summer, autumn, and winter, respectively. Increasing trends of the mean temperature occurred in all seasons, with the largest variation of the MTA in winter, then spring and autumn, and the smallest variation of the MTA in summer (Figure 3). The transition point of the MTA of the seasonal mean temperature was also 1980, similar to the MTA of the 


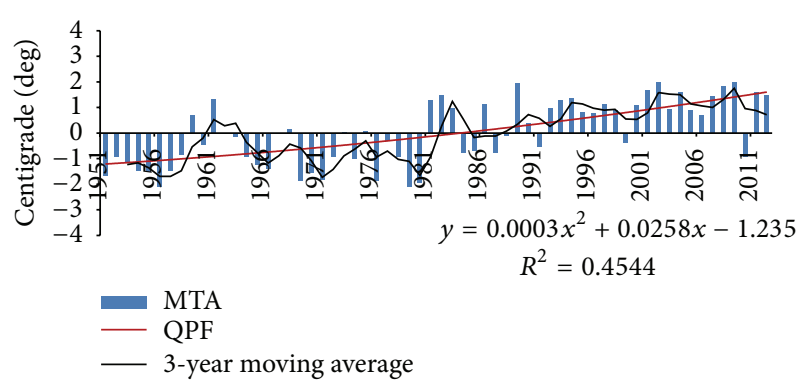

(a)

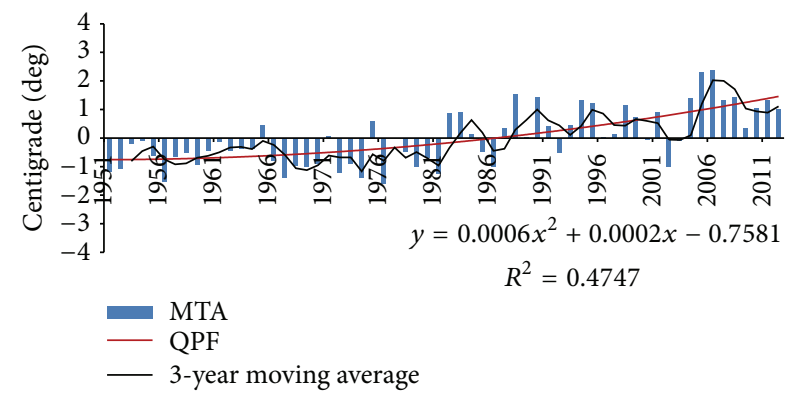

(c)

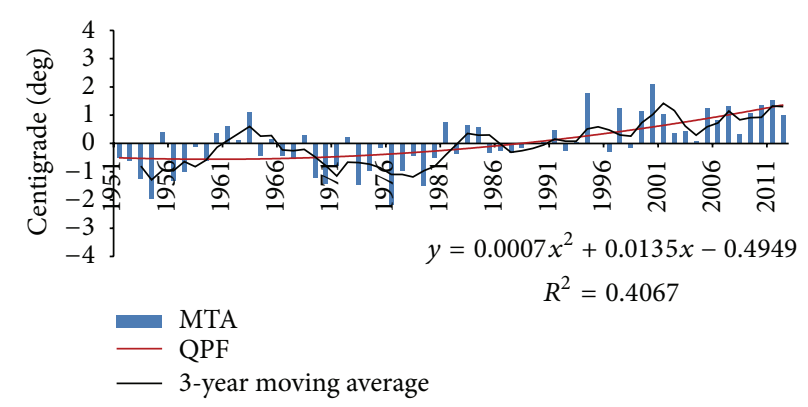

(b)

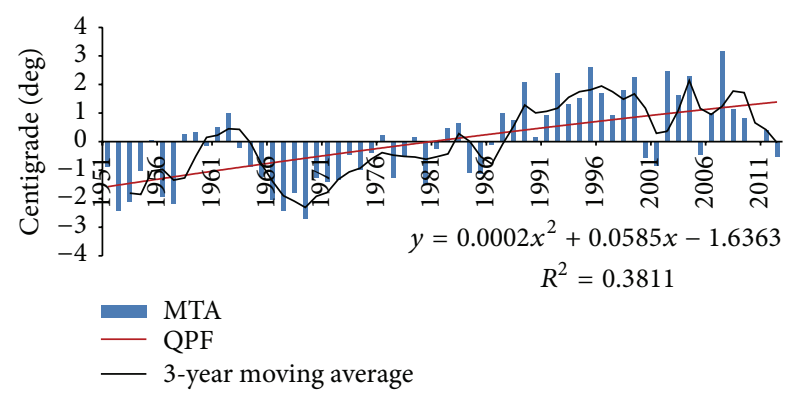

(d)

Figure 3: The Mean Temperature Anomaly (MTA), Quadratic Polynomial Fitting (QPF), and a 3-year moving average of the mean temperature of spring (a), summer (b), autumn (c), and winter (d) of Guan Xiang Tai (GXT) in the period of 1951-2012.

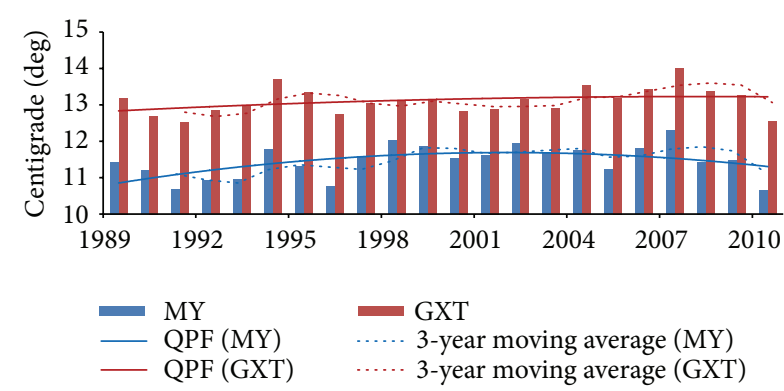

(a)

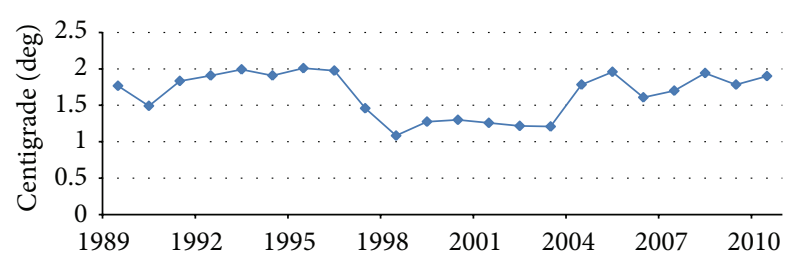

(b)

Figure 4: The annual mean temperature, Quadratic Polynomial Fitting (QPF), and a 3-year moving average of Guan Xiang Tai (GXT) and Mi Yun (MY) (a) and temperature differences (b) between the two stations in the period of 1989-2010.

annual mean temperature. It is worth noting that while the MTA of the mean spring, autumn, and winter temperatures showed a decrease after 2007, the MTA of the mean summer temperature still increased slowly.

3.1.2. Temperature of the Urban and Rural Areas. Between 1989 and 2010, the average temperatures of GXT and MY were $13.1^{\circ} \mathrm{C}$ and $11.5^{\circ} \mathrm{C}$, respectively, with a mean temperature difference of $1.6^{\circ} \mathrm{C}$ between the two stations. The annual mean temperature of each station increased slightly from 1989 to 2007 and then decreased slightly (Figure 4). The temporal trends related to the temperature difference between GXT and MY can be divided into three periods: (1) 1989-1996, when the temperature difference was approximately $2^{\circ} \mathrm{C}$; (2) 1997-2003, when the temperature difference decreased to approximately $1.2^{\circ} \mathrm{C}$; and (3) 2004-2010, when the temperature difference increased by approximately $0.6^{\circ} \mathrm{C}$. Between 1989 and 1998, the annual mean temperature of MY increased faster than that of GXT, causing the decrease of the temperature difference.

The temporal variations of urban-rural differences of the mean temperature in autumn and winter fluctuated during the period from 1989 to 2010, especially after 2000, while those in spring and summer were much more stable and showed slight increases. The QPF of winter decreased slightly for both GXT and MY (Figure 5).

Winter and summer had the largest and smallest temperature differences, respectively, which is mainly due to the coal burning for central heating from November to March in Beijing [1]. The temporal variations of the seasonal temperature differences showed a consistent trend across the annual 


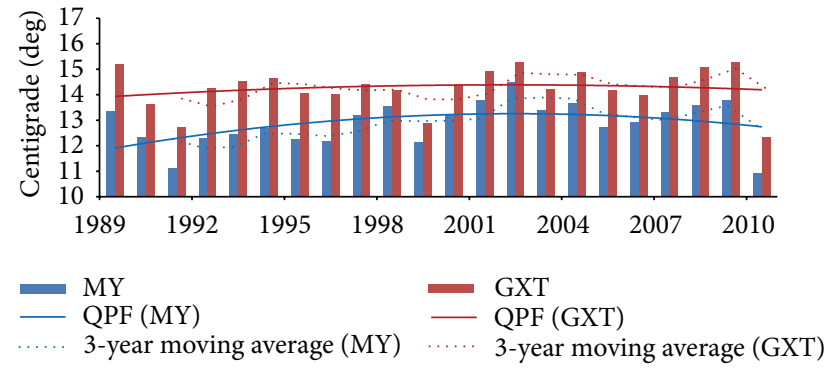

(a)

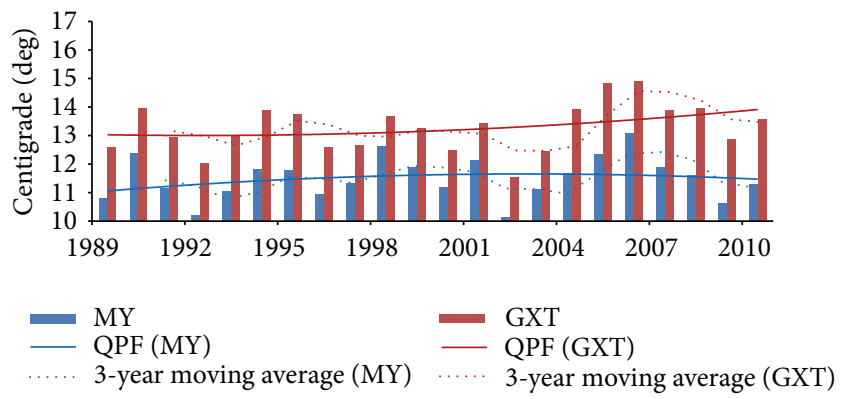

(c)

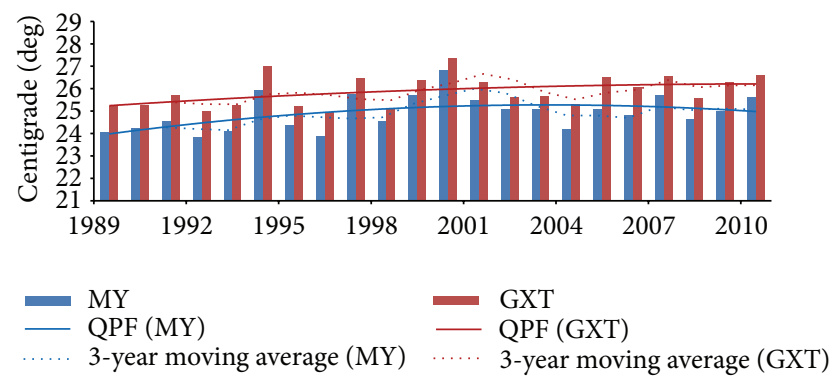

(b)

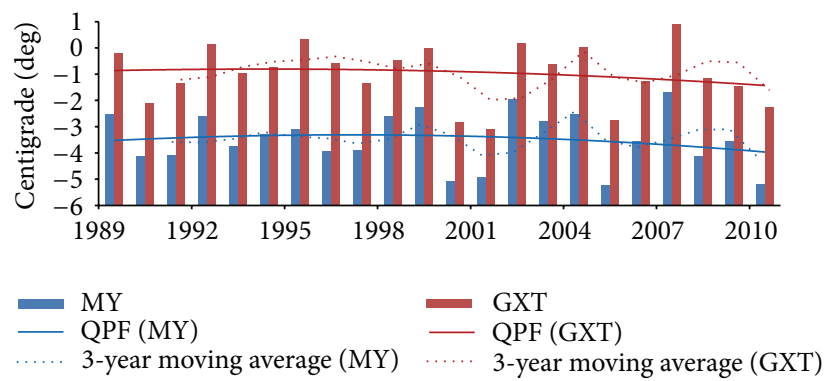

(d)

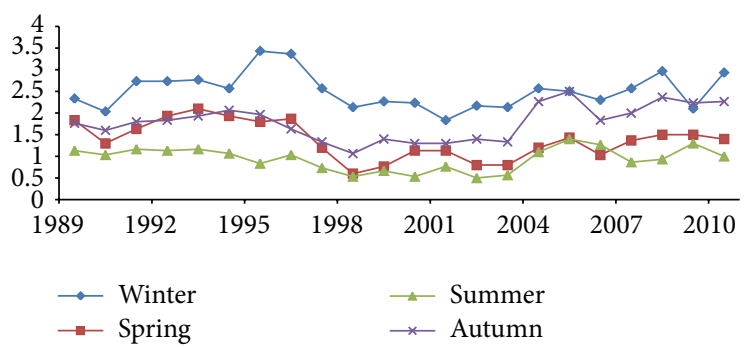

(e)

FIgure 5: The mean temperature and Quadratic Polynomial Fitting (QPF) of Guan Xiang Tai (GXT) and Mi Yun (MY) of spring (a), summer (b), autumn (c), and winter (d), and temperature differences (e) between the two stations in the period of 1989-2010.

temperature differences. Notably, the temperature difference during spring and autumn was similar before 1997. After 1997, the temperature difference of spring decreased more than that of autumn, and after 2004, the temperature difference of spring increased less than that of autumn. Consequently, the temperature difference of spring approached to that of summer, while the temperature difference of autumn tended towards that of winter.

3.2. Urban Development and Temperature Change. As the political, cultural, and educational center of China, Beijing, has attracted a large influx of population. By 2012, Beijing's resident population reached 20.693 million, which was 2.4 times greater than in 1978, with the population growth rate continuing to accelerate. The urban area of Beijing has grown to $1261 \mathrm{~km}^{2}$ in 2012, from $60 \mathrm{~km}^{2}$ in $1949,326 \mathrm{~km}^{2}$ in 1978 , and $834 \mathrm{~km}^{2}$ in 2004 . The urban area expanded nearly 17 times. The area under construction increased from 9 million $\mathrm{km}^{2}$ in 1978 to 200 million $\mathrm{km}^{2}$ in 2012, and the length of highway also increased from $6,562 \mathrm{~km}$ to $21,500 \mathrm{~km}$. Industrial development and population growth caused burgeoning energy consumption, increasing from 19 million tons of standard coal in 1978 to 72 million tons of standard coal in 2012 (Figure 6).

Urbanization has caused an increase of impervious surfaces, industrial energy consumption, domestic heating, and automobile exhaust emissions as well as a decrease of green land and water surface, and it has been shown that city development is changing the thermal conditions of the city in a variety of ways, thus affecting the local temperature [37]. Most studies have shown that Beijing's temperature increased significantly in the past half century. This study also showed an increasing trend in the annual mean temperature as well as the seasonal mean temperature, especially from 1971 to 1994, mostly due to the large temperature rise in winter and spring.

The urbanization of suburban and rural areas not only promoted the transfer of a large number of high-tech industries from the city to the suburbs and satellite towns, but also attracted a large number of people to these areas. According to the fifth and sixth censuses, the population of Beijing is mostly concentrated in the suburbs and surrounding districts, especially the urban expansion districts of Haidian, 


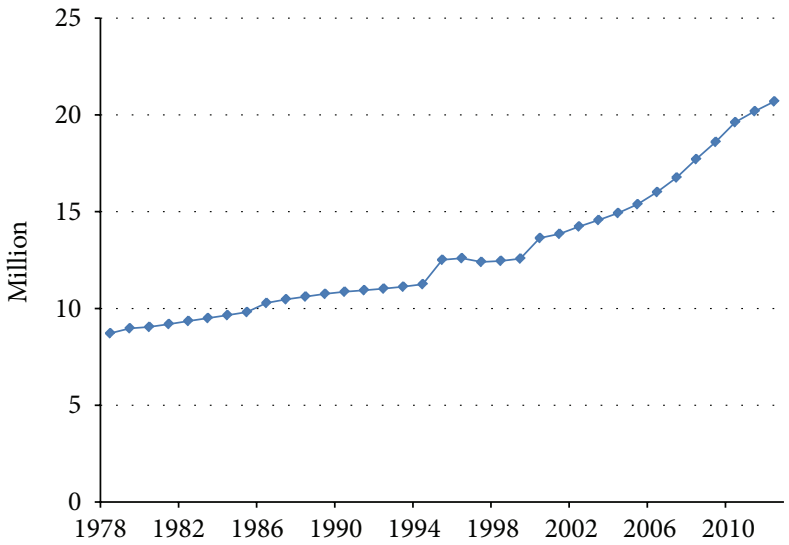

(a)

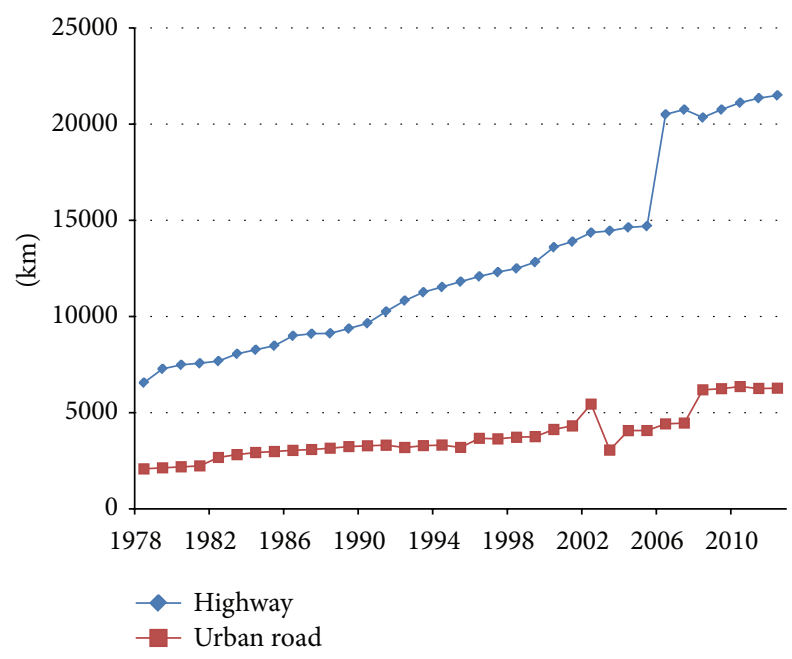

(c)

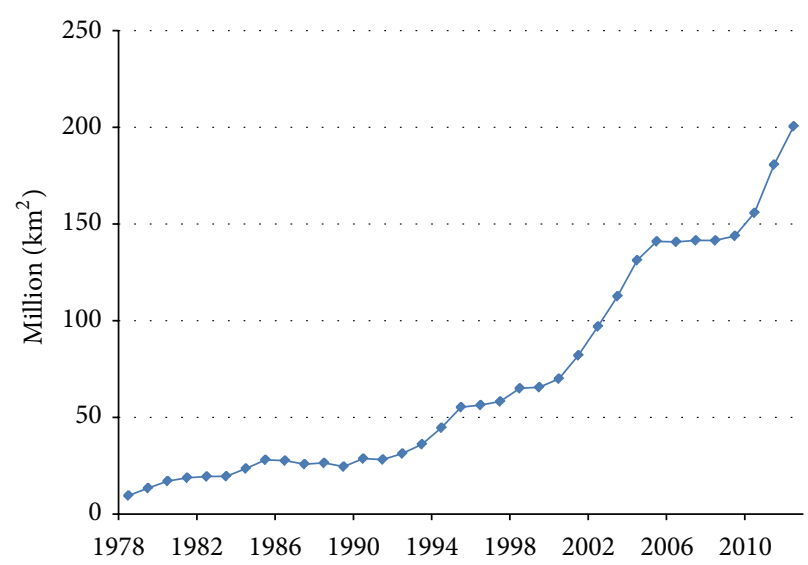

(b)

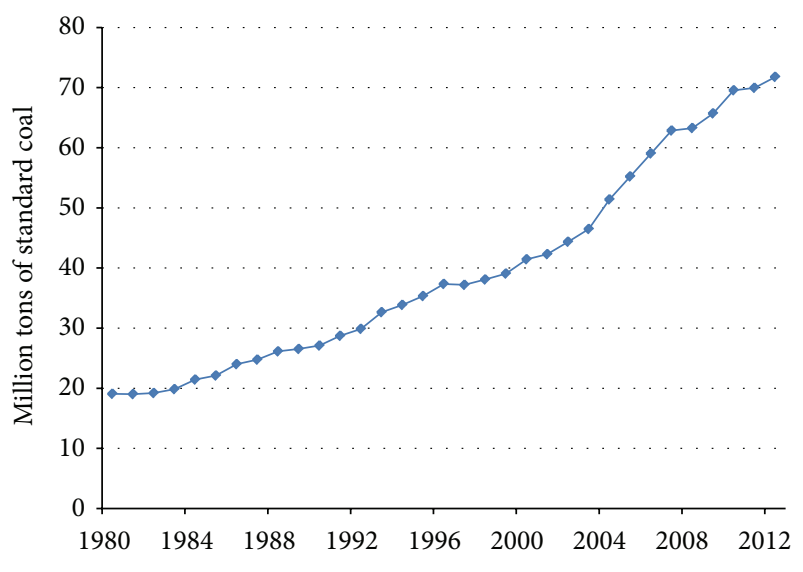

(d)

Figure 6: Resident population (a), construction area (b), length of highway and urban road (c), and total energy consumption (d) of Beijing in the period of 1978-2012.

Chaoyang, Fengtai, and Shijingshan, which have become the most densely populated areas of the city (Figure 7). The temperature of rural Beijing, represented by the observations at MY, showed a faster increase than the temperature of the urban area during 1989-1998. This change was related to the rapid urbanization and the substantial population increase of the northern suburbs.

3.3. Land Use and Temperature Change. The relationship between temperature and land use change has received considerable research attention, including research on the impact of large-scale land use change on the global climate $[38,39]$ and the influence of local land use change on regional temperature [30, 40, 41].

From the land use change detection matrix for Beijing in the period of 1990-2010, it can be observed that land use change was more intensive before 2000, when there were many transfers between different land use types, especially an increase of built-up land (Tables 1 and 2). After 2000, transfers from cropland to built-up land continued, but the transfers between other land use types showed a substantial reduction (Table 3). After 2005, all types of transfers decreased (Table 4).

From 1951 to 2012, the annual mean temperature of GXT showed an overall upward trend, but the rate of the increase slowed after 1994 and there has even been a decrease since 2007. Between 1989 and 2010, the annual mean temperatures of GXT and MY only showed slight increases, and the winter temperatures decreased slightly. The temperature difference between the two stations increased after 2004. From the perspective of land use change, the large increase of builtup land and decrease of green land (cropland, woodland, and grassland) before 2000 have intensified the urban heat island effect and made a positive contribution to the regional warming. However, this part of the contribution was reduced when land use change decreased after 2000.

Since the reform and opening-up of China after 1978, the urbanization of Beijing can be divided into three stages: (1) 1978-1990, a stage of rapid development of urbanization, with an urbanization rate increase from $55 \%$ to $73.5 \%$ but with 
TABLE 1: Land use change detection matrix in the period of $1990-1995\left(\mathrm{~km}^{2}\right)$.

\begin{tabular}{|c|c|c|c|c|c|c|}
\hline \multirow{2}{*}{1990} & \multicolumn{6}{|c|}{1995} \\
\hline & Cropland & Woodland & Grassland & Water body & Built-up land & Unused land \\
\hline Cropland & - & 610.03 & 220.14 & 169.18 & 845.80 & 4.70 \\
\hline Woodland & 226.02 & - & 675.49 & 26.25 & 57.72 & 3.55 \\
\hline Grassland & 116.90 & 806.51 & - & 57.90 & 16.77 & 9.48 \\
\hline Water body & 28.95 & 22.05 & 10.08 & - & 12.93 & 0.03 \\
\hline Built-up land & 134.81 & 38.50 & 15.43 & 11.57 & - & 0.60 \\
\hline Unused land & 0.06 & 0.49 & 0.27 & & & - \\
\hline LUDI (\%) & -4.58 & 1.34 & -1.26 & 9.54 & 9.95 & 303.64 \\
\hline BLUDI (\%) & 8.04 & 6.77 & 28.29 & 16.94 & 15.41 & 332.18 \\
\hline
\end{tabular}

TABLE 2: Land use change detection matrix in the period of $1995-2000\left(\mathrm{~km}^{2}\right)$.

\begin{tabular}{|c|c|c|c|c|c|c|}
\hline \multirow{2}{*}{1995} & \multicolumn{6}{|c|}{2000} \\
\hline & Cropland & Woodland & Grassland & Water body & Built-up land & Unused land \\
\hline Cropland & - & 264.82 & 108.22 & 36.29 & 304.86 & 0.06 \\
\hline Woodland & 568.88 & - & 644.60 & 163.83 & 58.78 & 0.49 \\
\hline Grassland & 178.32 & 710.32 & - & 10.52 & 26.79 & 0.27 \\
\hline Water body & 76.45 & 29.09 & 28.03 & - & 27.06 & \\
\hline Built-up land & 288.77 & 58.34 & 9.73 & 16.57 & - & \\
\hline Unused land & 4.47 & 3.51 & 9.44 & 0.03 & 0.91 & - \\
\hline LUDI (\%) & 1.78 & -0.95 & -1.98 & 2.25 & 0.41 & -18.76 \\
\hline BLUDI (\%) & 8.11 & 6.44 & 27.03 & 13.12 & 7.18 & 20.53 \\
\hline
\end{tabular}

TABLE 3: Land use change detection matrix in the period of $2000-2005\left(\mathrm{~km}^{2}\right)$.

\begin{tabular}{|c|c|c|c|c|c|c|}
\hline \multirow{2}{*}{2000} & \multicolumn{6}{|c|}{2005} \\
\hline & Cropland & Woodland & Grassland & Water body & Built-up land & Unused land \\
\hline Cropland & - & 11.37 & 2.07 & 3.10 & 375.72 & \\
\hline Woodland & & - & 0.25 & 1.21 & 23.41 & \\
\hline Grassland & & 2.27 & - & 0.89 & 3.58 & \\
\hline Water body & 10.73 & 0.16 & 5.86 & - & 12.76 & \\
\hline Built-up land & 0.67 & 0.30 & & 0.51 & - & \\
\hline Unused land & & & & & & - \\
\hline LUDI (\%) & -1.55 & -0.03 & 0.02 & -0.93 & 3.68 & 0.00 \\
\hline BLUDI (\%) & 1.64 & 0.11 & 0.23 & 1.37 & 3.71 & 0.00 \\
\hline
\end{tabular}

TABLE 4: Land use change detection matrix in the period of $2005-2010\left(\mathrm{~km}^{2}\right)$.

\begin{tabular}{|c|c|c|c|c|c|c|}
\hline \multirow{2}{*}{2005} & \multicolumn{6}{|c|}{2010} \\
\hline & Cropland & Woodland & Grassland & Water body & Built-up land & Unused land \\
\hline Cropland & - & 0.07 & & 0.85 & 3.17 & \\
\hline Woodland & 0.05 & - & 0.03 & 0.01 & 1.08 & \\
\hline Grassland & & 0.02 & - & 0.01 & 0.02 & \\
\hline Water body & 11.13 & 3.50 & 0.01 & - & 2.15 & \\
\hline Built-up land & 7.07 & 1.15 & 0.02 & 2.23 & - & \\
\hline Unused land & & & & & & - \\
\hline LUDI (\%) & 0.06 & 0.01 & 0.00 & -0.56 & -0.03 & 0.00 \\
\hline BLUDI (\%) & 0.10 & 0.02 & 0.00 & 0.81 & 0.13 & 0.00 \\
\hline
\end{tabular}




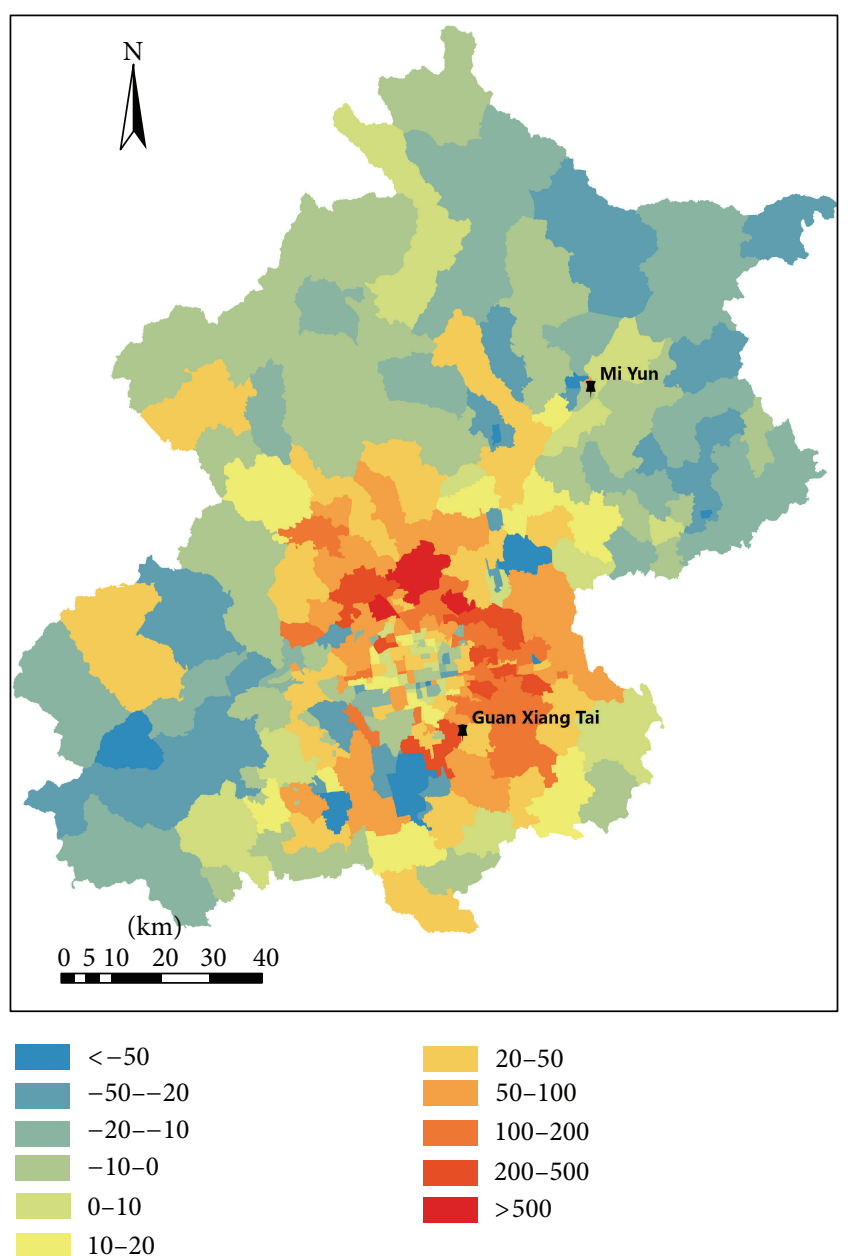

FIGURE 7: Population Growth Rate (PGR) of towns of Beijing in the period of 2000-2010.

a low level of urban infrastructure, without obvious urban sprawl; (2) 1990-2005, a stage of improvement of urbanization, with an urbanization rate increase from $73.5 \%$ to $83.6 \%$, and the city underwent intensive expansion; and (3) 20052012 , a stage of new urbanization, with an urbanization rate increase from $83.6 \%$ to $86.2 \%$ and urban-rural integration. The process of urbanization showed a temporal consistency with decreased land use change and increased temperatures.

The district of Mi Yun, in which the station MY is located, has been regarded as a district dedicated to ecological conservation. Ecological protection, water conservation, tourism, and ecological agriculture became the main directions of development for this district. Consequently, economic restructuring and improvement of urban planning may have been one of the reasons that the regional warming has been ameliorated.

\section{Conclusion}

Affected by city development and global warming, the temperature of urban Beijing, represented by the observations at GXT, increased apparently during the period from 1951 to 2012, especially from 1971 to 1994 . The temperature of rural Beijing, represented by the observations at MY, showed a faster increase than that of the urban area from 1989 to 1998. However, the rate temperature increase slowed down in recent years, and the winter temperature even decreased slightly between 1989 and 2010. These changes showed temporal consistency with the processes of land use change and urbanization in Beijing. Therefore, economic restructuring and improvement of urban planning may have been one of the reasons that the regional warming has been slowed down in the rural area. Nevertheless, the urban heat island effect in Beijing still needs further research attention, considering the city's large population growth and energy consumption.

\section{Conflict of Interests}

The authors declare that there is no conflict of interests regarding the publication of this paper.

\section{Acknowledgments}

This study was partially supported and funded by the General Program of Science and Technology Development Project of Beijing Municipal Education Commission (KM201310011010), the China Postdoctoral Science Foundation (20060400496), the Chinese Academy of Sciences (XDA05050102), and the National Scientific and Technological Support Projects of China (2011BAJ07B01-2). The authors are grateful to Professor Shenbin Chen of IGSNRR, CAS for his suggestions on the paper. In addition, the authors thank Ms. Sibo Hou of IGSNRR, CAS for her help in revising the paper.

\section{References}

[1] S. B. Chen and L. Q. Pan, "Effects of urbanization on the annual mean temperature of Beijing," Acta Geographica Sinica, vol. 52, no. 1, pp. 27-36, 1997.

[2] IPCC, "Climate Change," 2013, http://www.ipcc.ch/report/ ar5/wg1/\#.UlDShLKBSY8, http://www.climatechange2013.org/ images/uploads/WGI-AR5_SPMPressRelease.pdf.

[3] H. E. Landsberg, The Urban Climate, Academic Press, 1981.

[4] K. P. Gallo, D. R. Easterling, and T. C. Peterson, “The influence of land use/land cover on climatological values of the diurnal temperature range," Journal of Climate, vol. 9, no. 11, pp. 29412944, 1996.

[5] K. P. Gallo, T. W. Owen, D. R. Easterling, and P. F. Jamason, "Temperature trends of the U.S. historical climatology network based on satellite-designated land use/land cover," Journal of Climate, vol. 12, no. 5, pp. 1344-1348, 1999.

[6] D. R. Easterling, B. Horton, P. D. Jones et al., "Maximum and minimum temperature trends for the globe," Science, vol. 277, no. 5324, pp. 364-367, 1997.

[7] J. E. Hansen, W. Lawrence, D. Easterling et al., "A closer look at United States and global surface temperature change," Journal of Geophysical Research: Atmospheres, vol. 106, no. D20, pp. 2394723963, 2001.

[8] T. B. Zhao and C. B. Fu, "Applicability evaluation of surface air temperature from several reanalysis datasets in China," Plateau Meteorology, vol. 28, no. 3, pp. 594-606, 2009 (Chinese). 
[9] M. K. Kim and S. Kim, "Quantitative estimates of warming by urbanization in South Korea over the past 55 years (19542008)," Atmospheric Environment, vol. 45, no. 32, pp. 5778-5783, 2011.

[10] T. R. Karl, H. F. Diaz, and A. G. Kukl, "Urbanization: its detection and effect in the United States climate record," Journal of Climate, vol. 1, no. 11, pp. 1099-1123, 1988.

[11] G. Kukla, J. Gavin, and T. R. Karl, “Urban warming," Journal of Climate and Applied Meteorology, vol. 25, no. 9, pp. 1265-1270, 1986.

[12] Z. S. Xu, "Discussion on the status of city heat island and its causation in Beijing," Geographical Research, vol. 6, no. 3, pp. 159-168, 1987.

[13] G. Z. I. Zhang, X. D. Xu, J. Z. Wang et al., "A study on the characteristics and evolution of urban heat island over Beijing and its surrounding area," Journal of Applied Meteorological Science, vol. 13, pp. 43-50, 2002.

[14] Y. L. Song, W. J. Dong, S. Y. Zhang et al., "Study on characteristics of climate element in Beijing," Arid Meteorology, vol. 21, no. 3, pp. 63-68, 2003.

[15] X. C. Lin and S. Q. Yu, "Interdecadal changes of temperature in the Beijing region and its heat island effect," Chinese Journal of Geophysics, vol. 48, no. 1, pp. 39-45, 2005.

[16] L. Zhang, Z. X. Xu, and B. Q. Ruan, "Effect of urban heat island on the air temperature and precipitation in Beijing region," Journal of Natural Resources, vol. 21, no. 5, pp. 746-755, 2006.

[17] Z. W. Yan, Z. Li, Q. X. Li, and P. Jones, "Effects of site change and urbanisation in the Beijing temperature series 1977-2006," International Journal of Climatology, vol. 30, no. 8, pp. 12261234, 2010.

[18] L. Zhang, G. Y. Ren, J. Liu et al., "Urban effect on trends of extreme temperature indices at Beijing Meteorological Station," Chinese Journal of Geophysics, vol. 54, no. 5, pp. 1150-1159, 2011.

[19] J. Wang, Z. W. Yan, Z. Li, W. D. Liu, and Y. C. Wang, "Impact of urbanization on changes in temperature extremes in Beijing during 1978-2008," Chinese Science Bulletin, vol. 58, no. 36, pp. 4679-4686, 2013.

[20] Intergovernmental Panel on Climate Change, Climate Change 2007: The Physical Science Basis. Summary for Policymakers, Cambridge University Press, Cambridge, UK, 2007.

[21] J. Lean and D. A. Warrilow, "Simulation of the regional climatic impact of Amazon deforestation," Nature, vol. 342, no. 6248, pp. 411-413, 1989.

[22] A. Henderson-Sellers, R. E. Dickinson, T. B. Durbidge, P. J. Kennedy, K. McGuffie, and A. J. Pitman, "Tropical deforestation: modeling local-to regional-scale climate change," Journal of Geophysical Research, vol. 98, no. D4, pp. 7289-7315, 1993.

[23] Y. Xue, "The impact of desertification in the Mongolian and the Inner Mongolian grassland on the regional climate," Journal of Climate, vol. 9, no. 9, pp. 2173-2189, 1996.

[24] R. A. Pielke Sr., G. Marland, R. A. Betts et al., “The influence of land-use change and landscape dynamics on the climate system: relevance to climate-change policy beyond the radiative effect of greenhouse gases," Philosophical Transactions of the Royal Society A: Mathematical, Physical and Engineering Sciences, vol. 360, no. 1797, pp. 1705-1719, 2002.

[25] X. C. Yang, Y. L. Zhang, L. S. Liu, W. Zhang, M. J. Ding, and Z. F. Wang, "Sensitivity of surface air temperature change to land use/cover types in China," Science in China D: Earth Sciences, vol. 52, no. 8, pp. 1207-1215, 2009.
[26] Z. F. Zheng, Y. Zheng, and Q. C. Li, "Effect of urbanization on the temperature of Beijing metropolis in recent 30 years," Chinese Journal of Eco-Agriculture, vol. 15, no. 4, pp. 26-29, 2007 (Chinese).

[27] W. Z. Su, C. L. Gu, and G. S. Yang, "Assessing the impact of land use/land cover on urban heat island pattern in Nanjing City, China," Journal of Urban Planning and Development, vol. 136, no. 4, pp. 365-372, 2010.

[28] W. T. L. Chow and B. M. Svoma, "Analyses of nocturnal temperature cooling-rate response to historical local-scale urban land-use/land cover change," Journal of Applied Meteorology and Climatology, vol. 50, no. 9, pp. 1872-1883, 2011.

[29] M. Wang, X. Yan, X. Liu, and X. Zhang, “The contribution of urbanization to recent extreme heat events and a potential mitigation strategy in the Beijing-Tianjin-Hebei metropolitan area," Theoretical and Applied Climatology, vol. 114, no. 3-4, pp. 407-416, 2013.

[30] W. Cao, Q. Q. Shao, J. Y. Liu et al., "Impact of land use/land cover and its change on climate warming in Beijing area," Climatic and Environmental Research, vol. 18, no. 4, pp. 451-460, 2013.

[31] J. Liu, M. Liu, H. Tian et al., "Spatial and temporal patterns of China's cropland during 1990-2000: an analysis based on Landsat TM data," Remote Sensing of Environment, vol. 98, no. 4, pp. 442-456, 2005.

[32] J. Liu, Z. Zhang, X. Xu et al., "Spatial patterns and driving forces of land use change in China during the early 21st century," Journal of Geographical Sciences, vol. 20, no. 4, pp. 483-494, 2010.

[33] Y. Wang, D. Jiang, D. Zhuang, Y. Huang, W. Wang, and X. $\mathrm{Yu}$, "Effective key parameter determination for an automatic approach to land cover classification based on multispectral remote sensing imagery," PloS ONE, vol. 8, no. 10, Article ID e75852, 2013.

[34] C. A. Berlanga-Robles and A. Ruiz-Luna, "Land use mapping and change detection in the coastal zone of northwest Mexico using remote sensing techniques," Journal of Coastal Research, vol. 18, no. 3, pp. 514-522, 2002.

[35] X. Wang and Y. Bao, "Study on the methods of land use dynamic change research," Progress in Geography, vol. 18, no. 1, pp. 81-87, 1999.

[36] H.-Z. Wang, R.-D. Li, and H.-H. Wu, "Bilateral change dynamic degree model for land use and its application to the land use study of suburban areas of Wuhan," Remote Sensing for Land \& Resources, vol. 14, no. 2, pp. 20-33, 2002.

[37] P. Shao and X. Zeng, "Progress in the study of the effects of land use and land cover change on the climate system," Climate and Environmental Research, vol. 1, pp. 103-111, 2012.

[38] T. N. Chase, R. A. Pielke Sr., T. G. F. Kittel, R. R. Nemani, and S. W. Running, "Simulated impacts of historical land cover changes on global climate in northern winter," Climate Dynamics, vol. 16, no. 2-3, pp. 93-105, 2000.

[39] D. Werth and R. Avissar, "The local and global effects of Amazon deforestation," Journal of Geophysical Research: Atmospheres, vol. 107, no. D20, pp. LBA 55-1-LBA 55-8, 2005.

[40] B. Stone Jr., "Land use as climate change mitigation," Environmental Science \& Technology, vol. 43, no. 24, pp. 9052-9056, 2009.

[41] W. Wang, W. Shen, X. Liu et al., "Research on the relation of the urbanization and urban heat island effect changes in Beijing based on remote sensing," Research of Environmental Sciences, vol. 19, no. 2, pp. 44-48, 2006. 

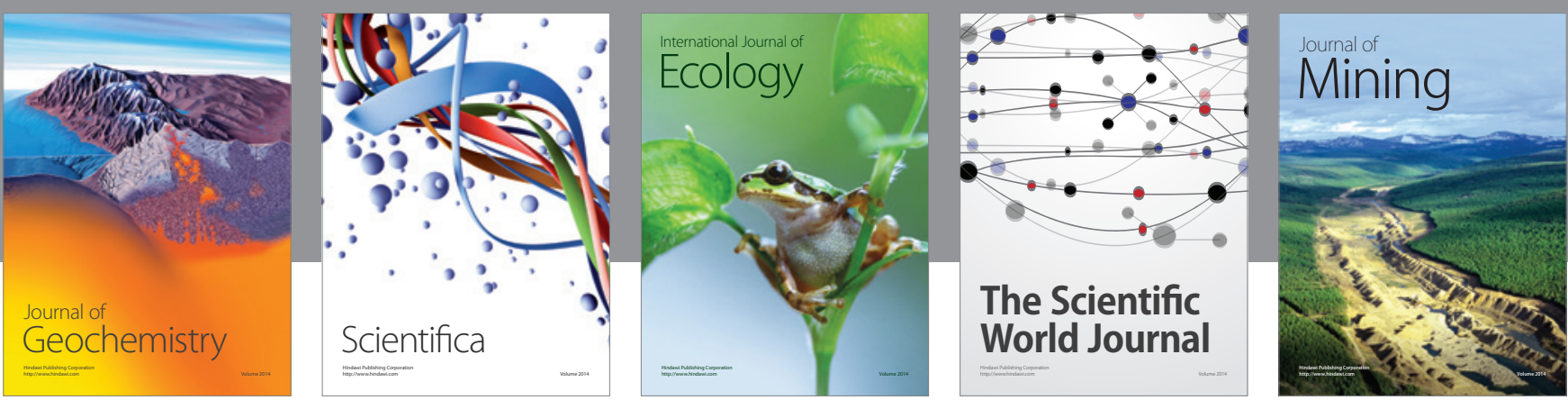

The Scientific World Journal
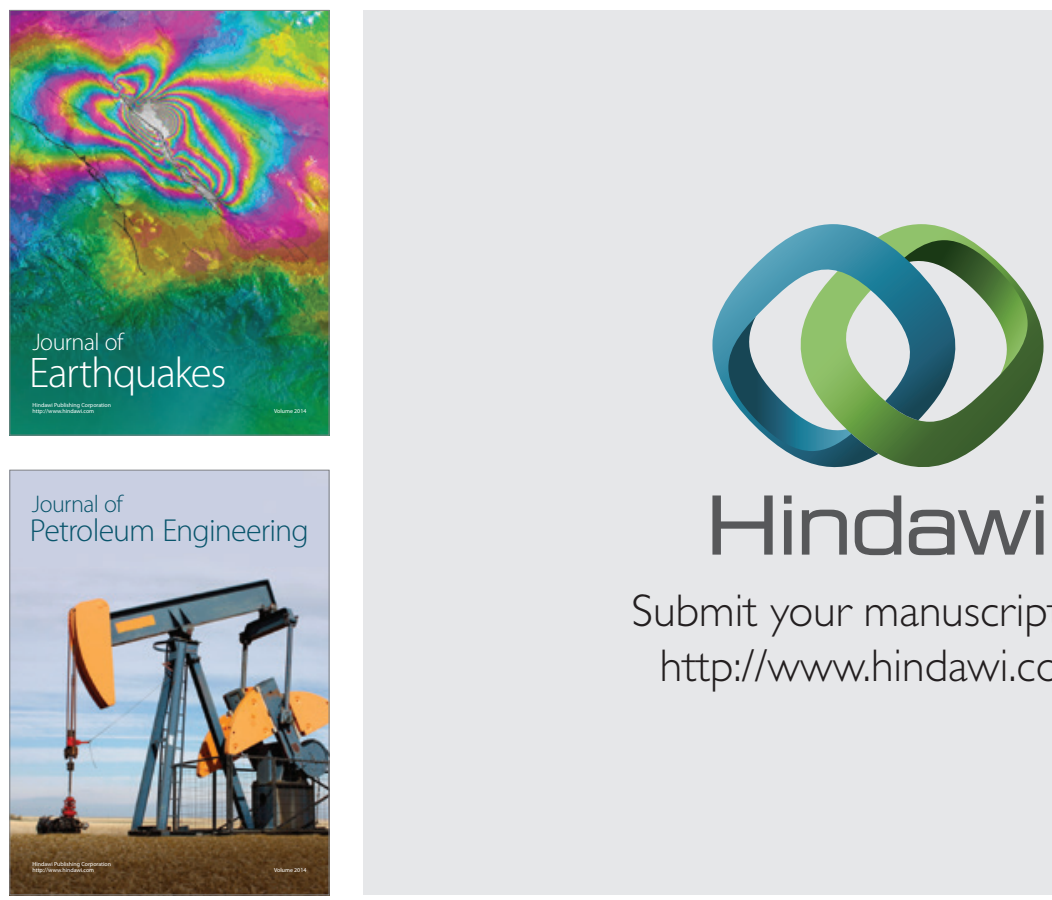

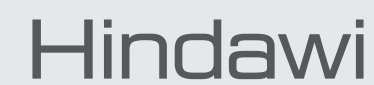

Submit your manuscripts at

http://www.hindawi.com
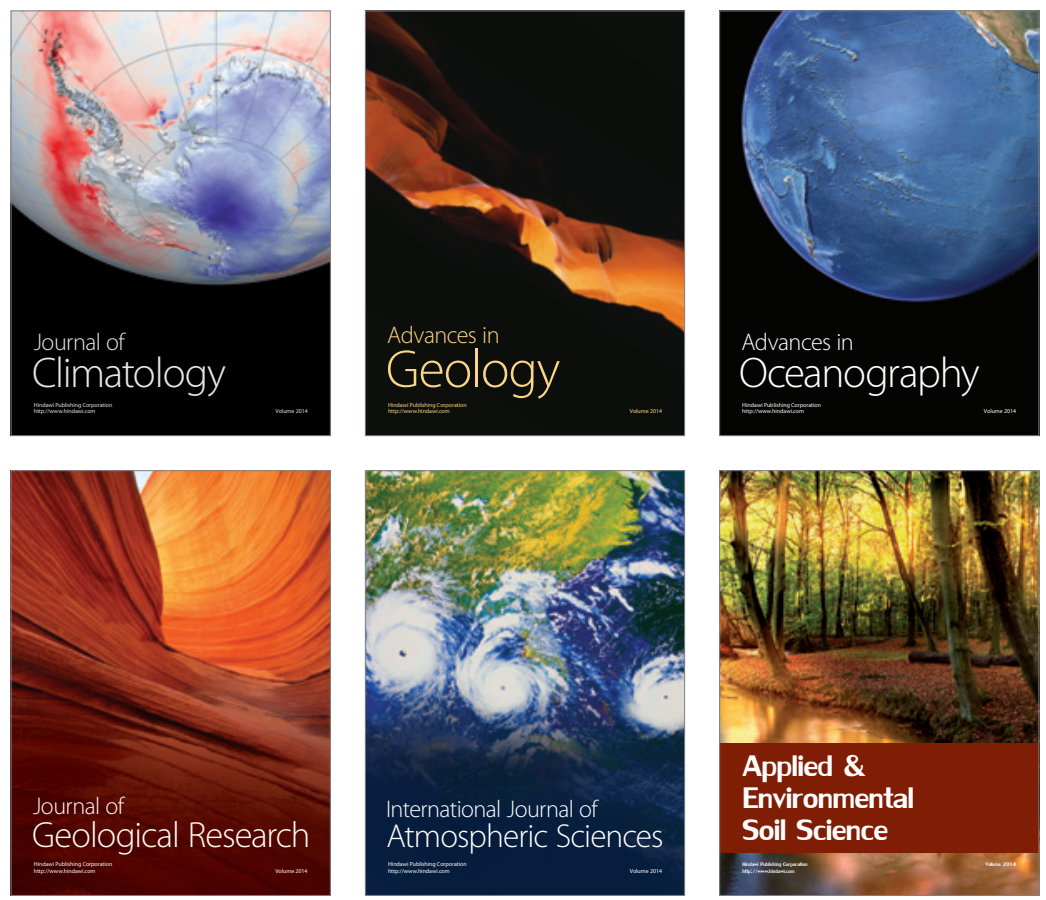
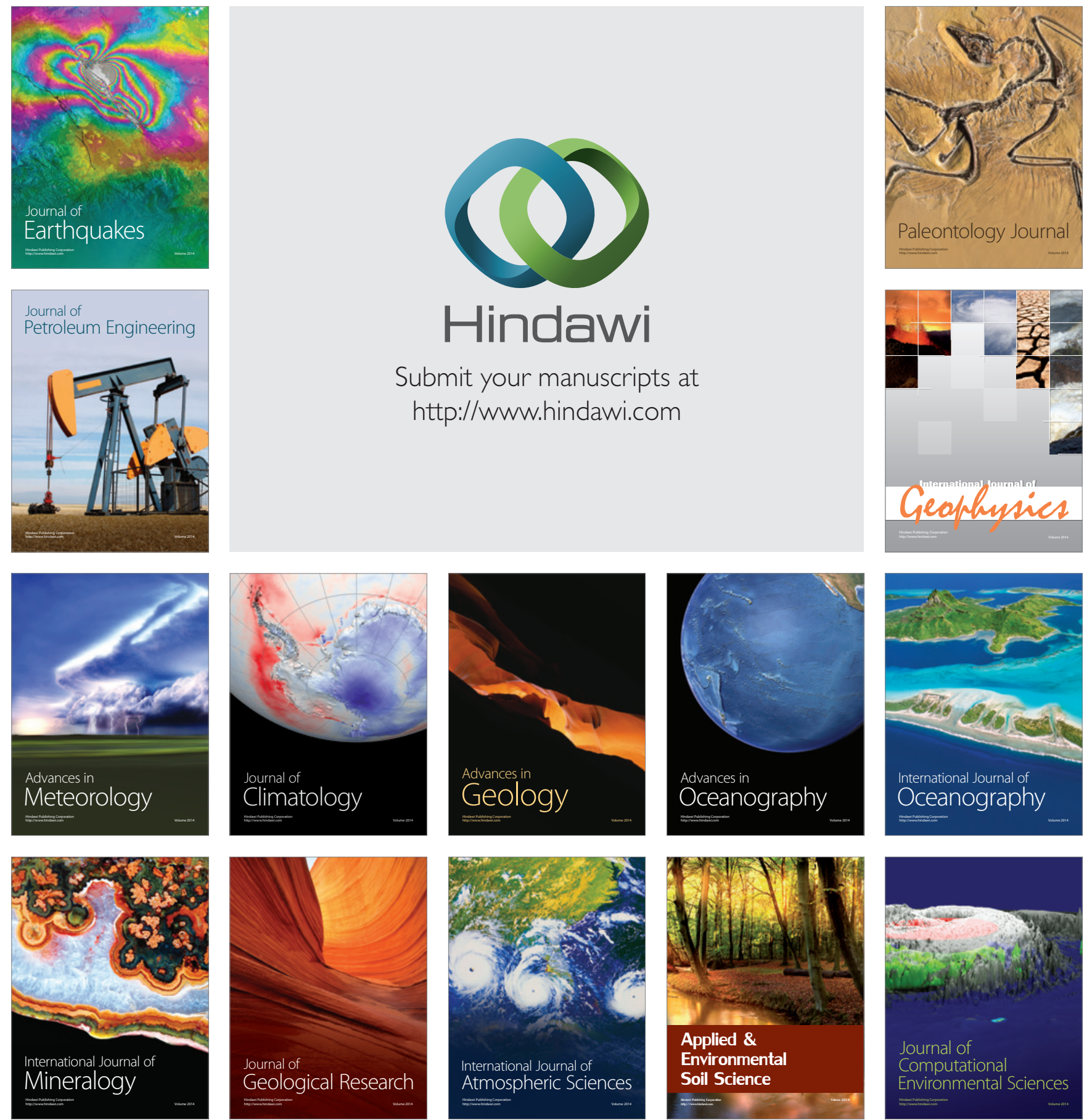